\title{
Effects of Eprosartan on Diastolic Function and Neurohormones in Patients with Hypertension and Diastolic Dysfunction
}

\author{
Adriaan A. Voors • Ruud M. van de Wal • Jasper W. L Hartog • Richard G. Vijn • \\ Yoran M. Hummel • Thijs W. M. Plokker • Dirk J. van Veldhuisen • Wybren Jaarsma
}

Published online: 13 March 2010

(C) The Author(s) 2010. This article is published with open access at Springerlink.com

\begin{abstract}
Objective To compare the effects of an angiotensin receptor blocker(ARB)-based regimen versus a non-ARB based regimen on diastolic function and neurohormones in patients with hypertension and diastolic dysfunction.

Methods 97 patients with a systolic blood pressure (SBP) $\geq 140 \mathrm{mmHg}$, a left ventricular ejection fraction $>0.50$, and echocardiographic evidence of diastolic dysfunction were randomly assignment to open-label treatment with eprosartan (with other anti-hypertensives; $n=47$ ) or other antihypertensives alone $(n=50)$. Echocardiography, including tissue Doppler imaging (TDI), and neurohormones were done at baseline and after 6 months.

Results Mean age was $65( \pm 10)$ years and 64\% was female. During 6 months of treatment, SBP decreased from $157 \pm 16$ to $145 \pm 18 \mathrm{mmHg}$ in the eprosartan group and from $158 \pm 17$ to $141 \pm 18 \mathrm{mmHg}$ in the control group (both $p<0.001 ; p=\mathrm{ns}$ between groups). Diastolic function was unaffected in both groups and there was no correlation between changes in SBP and changes in mean TDI $(r=-0.06 ; p=0.58)$. Aldosterone levels decreased in
\end{abstract}

\footnotetext{
A. A. Voors $(\bowtie) \cdot J$. W. L Hartog • Y. M. Hummel

D. J. van Veldhuisen PO Box 30.001, 9700 RB Groningen, The Netherlands

e-mail: a.a.voors@thorax.umcg.nl

R. M. van de Wal · T. W. M. Plokker • W. Jaarsma

St. Antonius Hospital Nieuwegein,

Nieuwegein, The Netherlands

R. G. Vijn

Refaja Hospital Stadskanaal,

Stadskanaal, The Netherlands
}

Department of Cardiology, University Medical Centre Groningen, the eprosartan group, but other neurohormones remained largely unchanged. Change in SBP was however related to the change in NT-proBNP $(r=0.26 ; p=0.019)$.

Conclusion Lowering blood pressure, either with eprosartan or other anti-hypertensives in hypertensive patients with diastolic dysfunction did not change diastolic function after 6 months of treatment, but was associated with a decrease of NT-proBNP.

Key words Hypertension · Heart failure - Blood pressure · Diastolic function - Tissue doppler - Neurohormones .

Natriuretic peptides

\section{Introduction}

Long-term hypertension is often accompanied by an impaired relaxation of the ventricles due to diastolic dysfunction. The presence of diastolic dysfunction, in particular when measured with tissue Doppler, is not only related to a greater risk of the development of heart failure, but is also associated with a poor prognosis [1].

Diastolic dysfunction is often present in combination with hypertension and left ventricular hypertrophy. Several antihypertensive agents have proven to effectively reduce left ventricular hypertrophy. However, meta-analyses have indicated that with the same blood pressure reduction, angiotensin receptor blockers are more effective in the reduction of left ventricular hypertrophy than other antihypertensive drugs [2]. In addition, angiotensin receptor blockers have more pronounced effects on the reduction of myocardial fibrosis compared with other antihypertensives [3-5]. Therefore, the effects of angiotensin receptor blockers on diastolic function are expected to be better than other anti-hypertensive drugs. 
A few smaller studies demonstrated beneficial effects of losartan, irbesartan, and telmisartan on diastolic function [6-12]. However, a recent randomised clinical trial did not demonstrate superiority of an angiotensin receptor blocker over control therapy in improving diastolic function in patients with hypertension and diastolic dysfunction [13]. Despite a slightly larger drop in blood pressure in the valsartan group, there was no difference in diastolic function after 9 months of treatment. Whether treatment in VALIDD was related to changes in neurohormonal activation remains unknown, since no data on neurohormonal changes were reported. This can be important, since changes in (NT-pro) BNP and other neurohormones might indicate an early change in cardiac filling pressures, potentially leading to structural and functional cardiac changes.

We conducted a prospective, randomised study to evaluate the effects of the angiotensin receptor blocker eprosartan versus control anti-hypertensive therapy on diastolic function and neurohormonal changes in patients with hypertension and diastolic dysfunction.

\section{Methods}

\section{Design}

The "effects of Eprosartan on Echocardiographic and Neurohormonal parameters of Diastolic dysfunction in hypertensive patients (EEND) study" was a prospective, randomised, open label trial, with blinded endpoint evaluation (PROBE).

\section{Patients}

From 2004 to 2007, 97 patients with hypertension and signs of diastolic dysfunction were randomised in three centres in the Netherlands. Patients older than 18 years, with hypertension (blood pressure $\geq 140 / 90$ ), who were not yet treated with an angiotensin II-AT1 receptor antagonist, underwent routine echocardiography and were screened for signs of diastolic dysfunction.

Patients were eligible to participate if left ventricular ejection fraction (LVEF) was $>50 \%$, and E/A-ratio was $<1$ in combination with either a deceleration time (DCT) $>280 \mathrm{~ms}$ or an isovolumetric relaxation time (IVRT) $>105 \mathrm{~ms}$. Exclusion criteria were recent myocardial infarction ( $<6$ weeks), unstable angina pectoris, severe valvular disease, acute heart failure, atrial fibrillation, pacemaker, history of drugsensitivity or allergy for eprosartan, pregnancy of lactation, clinical significant liver or renal disease, infection, and previous poor quality echocardiogram. Patients were randomized between eprosartan $600 \mathrm{mg}$ once daily ( $400 \mathrm{mg} 2$ weeks loading dose) and other anti-hypertensives $(n=47)$ or other anti-hypertensives alone $(n=50)$ for a period of 6 months.
Other anti-hypertensives that were allowed included ACEinhibitors, $\beta$-blockers, diuretics, calcium antagonists, but not ARBs. This study protocol was approved by the institutional review committee and all patients provided written informed consent.

\section{Procedures}

Patients were screened at the outpatient of the St. Antonius Hospital, Nieuwegein, the University Medical Centre Groningen, Refaja Hospital Stadskanaal, the Netherlands.

All patients who met the screening criteria signed informed consent and were referred for echocardiographic screening. After echocardiography, a baseline visit was performed, which included medical history, current medication use, physical examination, including systolic and diastolic blood pressure measurements (mean of three recordings after $5 \mathrm{~min}$ in supine position); ECG, routine laboratory screening, including haemoglobin, haematocrit, creatinin, urea, sodium, potassium, cholesterol, LDLcholesterol, and triglycerides.

Patients who fulfilled all inclusion and exclusion criteria were randomized to eprosartan or control treatment. Eprosar$\tan$ was administered as $400 \mathrm{mg}$ once daily during the first 2 weeks, and uptitrated to $600 \mathrm{mg}$ once daily, unless there were side effects. Additional anti-hypertensive therapy was allowed when the control blood pressure of $<140 / 90 \mathrm{mmHg}$ was not achieved. In the control arm, all other anti-hypertensive agents, except angiotensin receptor blockers, were allowed to reach the target blood pressure of $<140 / 90 \mathrm{mmHg}$.

After 6 weeks, a second outpatient clinic visit was performed, including changes in medication, registration of (serious) adverse events, medical history, physical examination. ECG, and routine laboratory screening. At 6 months, a final outpatient visit was performed, including the same assessments as the 6 weeks visit, and in addition an echocardiogram was performed. No patient was lost during follow-up.

\section{Echocardiography}

Patients underwent two-dimensional echocardiography, including colour flow mapping 2D-guided M-mode, blood pool and tissue Doppler echocardiography. Echocardiography was performed by experienced cardiac technicians using either a General Electric VIVID 7 system or a Philips 7500 Sonos System, with a $2.5 \mathrm{mHz}$ probe. Measurements of diastolic function were done in accordance with the most recent recommendations [14]. Measurements included left ventricular and atrial dimensions, the peak early (E) and late (A) diastolic filling velocities, isovolumetric relaxation time (IVRT), deceleration time (slope) of the early peak filling (DCT). Furthermore, using tissue Doppler imaging, 
early diastolic velocity $\left(\mathrm{E}^{\prime}\right)$ was measured on the lateral, septal, anterior, and inferior wall areas, and subsequently averaged (mean $\mathrm{E}^{\prime}$ ). $\mathrm{E} / \mathrm{E}^{\prime}$ was calculated by dividing the peak early diastolic filling (E) by the average $E^{\prime}$ measured using tissue Doppler imaging. In one centre (University Medical Centre Groningen), colour coded tissue Doppler (ccTDI) instead of pulsed wave tissue Doppler (pwTDI) was used. A recent comparison between ccTDI and pwTDI was conducted and yielded the following conversion formulas: $\left.\mathrm{E}^{\prime}(\mathrm{pwTDI})=1.6+1.2 \times \mathrm{E}^{\prime}(\mathrm{ccTDI})\right]$ and $\mathrm{E} / \mathrm{E}^{\prime}$ $($ pwTDI $)=1.3+0.6 \times \mathrm{E} / \mathrm{E}^{\prime}(\mathrm{ccTDI})$. We therefore presented all data as pwTDI. Relative wall thickness (RWT) was calculated as (interventricular wall thickness + left ventricular posterior wall thickness)/left ventricular enddiastolic diameter.

\section{Neurohormonal markers}

Venous blood samples and urine samples were taken at the outpatient clinic while the patient was in an upright position. The blood and urine samples were transported to the local laboratory immediately and each aliquot was processed and stored according to protocol for later batched analysis. The concentration of aldosterone was measured by a sandwich radioimmunoassay (Diagnostic Products Corporation, Breda, the Netherlands). Active renin protein was measured by an immunoradiometric assay (Nichols Institute Diagnostics, Middlesex, United Kingdom) and serum ACE activity was measured by an enzymatic assay (Bühlmann Laboratory AG, Schünenbuch, Swiss). NTprobrain natriuretic peptide (NTproBNP) was measured by an Elecsys NT-proBNP immunoassay (Roche Diagnostics, Mannheim, Germany). Renal function was expressed as estimated GFR (eGFR), calculated with the simplified MDRD formula [15]. Analyses were performed in a routine setting according to the guidelines of the manufacturer.

\section{Statistical analysis}

The EEND study is considered to be a pilot study. As no data were available on this subject at the time of initiation of the study, formal calculation of the sample size was not performed. Participants who met all inclusion criteria and had no exclusion criteria were randomized in a 1:1 ratio to standard treatment or standard treatment combined with eprosartan $600 \mathrm{mg}$ once daily. Between-group differences were analyzed according to the intention-to-treat principle. Endpoints of interest were:

a) Change in diastolic function, measured with the mean tissue Early ( $\left.E^{\prime}\right)$ velocity;

b) Change in diastolic function, measured with $\mathrm{E} / \mathrm{E}^{\prime}$;

c) Change in neurohormonal markers

Data were analyzed using SAS version 9.1. Continuous variables were expressed as means \pm SD or as median $[25$ $75 \%$ interquartile range], where applicable. Nominal variables are expressed as $n(\%)$. Baseline characteristics were analysed for difference over treatment group by using student's $t$ test or Mann-Whitney U test where applicable for continuous variables and by chi-square using nominal variables. The effects of eprosartan on diastolic function were evaluated using student's $t$ test or Mann-Whitney U test where applicable. The relation between change in blood pressure (tertiles) and change in NT-proBNP was tested using ANOVA. A $p$-value $P \leq 0.05$ (two-sided) was considered statistically significant.

\section{Results}

Data were analysed from 97 patients (35 male) aged $65 \pm$ 10 years who were randomly assigned to 6 months openlabel treatment with either eprosartan (in combination with

Table 1 Baseline characteristics

$A M I$ acute myocardial infarction; $e G F R$ estimated glomerular filtration rate; $s M D R D$ simplified modification of diet in renal disease equation

\begin{tabular}{lccc}
\hline & $\begin{array}{l}\text { Eprosartan } \\
N=47\end{array}$ & $\begin{array}{l}\text { Control } \\
N=50\end{array}$ & $p$-value \\
& \multicolumn{1}{c}{$\begin{array}{l}\text { N } \\
\text { Mean age (years } \pm \text { SD) }\end{array}$} & $63.9( \pm 9.7)$ & 0.52 \\
\% Female & $30(65 \%)$ & $31(62 \%)$ & 0.74 \\
Body mass index & $28.7( \pm 4.2)$ & $29.2( \pm 5.3)$ & 0.63 \\
Heart failure & $11(23 \%)$ & $9(18 \%)$ & 0.51 \\
Current smoking & $8(17 \%)$ & $8(16 \%)$ & 0.89 \\
Diabetes & $5(11 \%)$ & $6(12.0 \%)$ & 0.51 \\
History of AMI & $0(0 \%)$ & $2(4 \%)$ & 0.17 \\
NT-proBNP (pg/ml) & $113( \pm 101)$ & $125( \pm 139)$ & 0.63 \\
Creatinin $(\mu \mathrm{mol} / \mathrm{L})$ & $84( \pm 20.8)$ & $78.6( \pm 16.6)$ & 0.52 \\
eGFR $(\mathrm{sMDRD}) \mathrm{ml} / \mathrm{min} / 1.73 \mathrm{~m}^{2}$ & $73.5( \pm 16.0)$ & $5.2( \pm 1.0)$ & 0.13 \\
Cholesterol $(\mathrm{mmol} / \mathrm{l})$ & $5.2( \pm 1.2)$ & 0.14 \\
\hline
\end{tabular}


Table 2 Anti-hypertensive drugs other than eprosartan at baseline and at the end of the study at 6 months in the eprosartan and control groups

\begin{tabular}{|c|c|c|c|c|c|c|}
\hline & \multicolumn{3}{|l|}{ baseline } & \multicolumn{3}{|l|}{6 months } \\
\hline & Eprosartan $(n=47)$ & Control $(n=50)$ & $p$-value & Eprosartan $(n=45)$ & Control $(n=47)$ & $p$-value \\
\hline ACE-inhibitor & $19(40 \%)$ & $24(48 \%)$ & 0.45 & $12(27 \%)$ & $24(51 \%)$ & 0.02 \\
\hline Betablocker & $17(36 \%)$ & $18(36 \%)$ & 0.97 & $17(39 \%)$ & $24(51 \%)$ & 0.23 \\
\hline Calcium-antagonist & $9(19 \%)$ & $9(18 \%)$ & 0.92 & $11(24 \%)$ & $18(38 \%)$ & 0.15 \\
\hline Diuretic & $12(26 \%)$ & $18(36 \%)$ & 0.26 & $20(44 \%)$ & $31(66 \%)$ & 0.04 \\
\hline
\end{tabular}

other anti-hypertensives; $n=47$ ) or other anti-hypertensives alone $(n=50)$. Baseline characteristics are depicted in Table 1. According to the definition of the 2007 Guidelines of the European Society of Hypertension [16], at randomization $2(2 \%)$ patients had normal blood pressure, $2(2 \%)$ had high-normal blood pressure, 30 (31\%) patients had grade $1,21(22 \%)$ grade 2 , and $10(10 \%)$ grade 3 hypertension, and $32(33 \%)$ were classified as having isolated systolic hypertension. Twenty patients $(21 \%)$ had chronic heart failure. These chronic heart failure patients were stable and on medication for at least 3 months. Only few patients had diabetes mellitus (11\%).

Anti-hypertensive treatment at baseline and at the end of follow-up in both groups is depicted in Table 2. As expected, more anti-hypertensives were used in the control group compared with the eprosartan group.

\section{Blood pressure changes}

Baseline systolic and diastolic blood pressure were $158 \pm$ $17 \mathrm{mmHg}$ and $91 \pm 10 \mathrm{mmHg}$, and was comparable between the eprosartan $(157 \pm 16 \mathrm{mmHg})$ and control group (158 \pm $17 \mathrm{mmHg}$ ) (Fig. 1). After 6 months of treatment, systolic blood pressures were significantly lower, both in the eprosartan group (145 $\pm 18 \mathrm{mmHg} ; p<0.001$ vs. baseline) and in the control group $(141 \pm 18 \mathrm{mmHg} ; p<0.001$ vs. baseline; $p=\mathrm{ns}$ between groups). Changes in systolic $(-13 \pm$ $19 \mathrm{mmHg}$ vs. $-16 \pm 17 \mathrm{mmHg} ; p$ between groups $=0.38)$ and diastolic blood pressure $(-7 \pm 10 \mathrm{mmHg}$ vs. $-7 \pm 10 \mathrm{mmHg}$; $p$ between groups $=0.74$ ), were similar in the eprosartan and control groups respectively. The changes in systolic and diastolic blood pressure between baseline and 6 months are depicted in Fig. 1.

\section{Echocardiographic changes}

The echocardiographic findings at baseline and after 6 months are described in Table 3. Despite a significant drop in blood pressure, diastolic function remained largely unchanged in both groups. Mean TDI in the eprosartan group was $8.0 \pm 2.3 \mathrm{~cm} / \mathrm{s}$ at baseline and $8.3 \pm 2.2 \mathrm{~cm} / \mathrm{s}$ after 6 months, and $8.4 \pm 2.1 \mathrm{~cm} / \mathrm{s}$ and $8.5 \pm 2.0 \mathrm{~cm} / \mathrm{s}$ respectively at baseline and after 6 months in the control group (Fig. 2). Mean $\mathrm{E} / \mathrm{E}^{\prime}$ remained unchanged both in the eprosartan group (baseline: $9.3 \pm 4.0 ; 6$ months: $9.4 \pm 4.2$ ) and in the control group (baseline: $8.7 \pm 2.5$; 6 months: $8.9 \pm 3.5)$; $(p=$ NS both for changes within and between groups).

Additional analyses showed no correlation between the changes in SBP and the changes mean TDI $(r=-0.06 ; p=$ $0.58)$ or the change in $\mathrm{E} / \mathrm{E}^{\prime}(r=0.13 ; p=0.24)$.

\section{Changes in neurohormonal markers}

In the overall group, no significant effects were found on neurohormones in both groups between baseline and 6 months of treatment (NT-proBNP: $-2.8 \mathrm{pg} / \mathrm{ml} ; p=0.81$, renin $+6.1 \mathrm{pg} / \mathrm{ml} ; p=0.06$; aldosterone $-23 \mathrm{pg} / \mathrm{ml} ; p=0.20$; ACE $-0.56 \mathrm{pg} / \mathrm{ml} ; p=0.63$ ) However, aldosterone was significantly lower after 6 months in the eprosartan group compared to the control group. (Table 4) Changes in NTproBNP and other neurohormonal markers in the eprosartan and control groups are described in Table 4.

We found no correlation between the change in diastolic function and the change in NT-proBNP. However, a modest correlation was found between the reduction in systolic blood

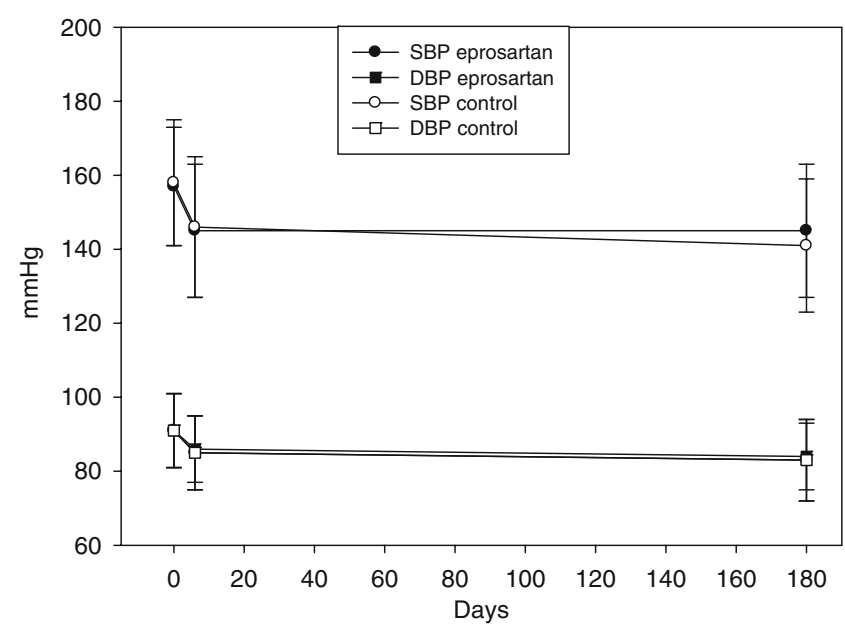

Fig. 1 Changes in systolic blood pressure (SBP) between baseline and after 6 months in the eprosartan and control group 
Table 3 Echocardiographic characteristics

\begin{tabular}{|c|c|c|c|c|c|}
\hline & \multicolumn{2}{|l|}{ Eprosartan } & \multicolumn{2}{|l|}{ Control } & \multirow[t]{2}{*}{$p$-value between groups at 6 months } \\
\hline & Baseline & 6 months & Baseline & 6months & \\
\hline $\mathrm{E} / \mathrm{A}$ ratio & $0.85( \pm 0.26)$ & $0.85( \pm 0.17)$ & $0.84( \pm 0.21)$ & $0.93( \pm 0.26)$ & 0.09 \\
\hline DC time $(\mathrm{ms})$ & $238( \pm 48)$ & $240( \pm 58)$ & $246( \pm 60)$ & $221( \pm 50)$ & 0.83 \\
\hline IVRT (ms) & $102( \pm 24)$ & $99( \pm 21)$ & $103( \pm 27)$ & $103( \pm 24)$ & 0.39 \\
\hline Mean $E^{\prime}(\mathrm{cm} / \mathrm{s})$ & $8.0( \pm 2.3)$ & $8.3( \pm 2.2)$ & $8.4( \pm 2.1)$ & $8.5( \pm 2.0)$ & 0.48 \\
\hline LVMI (g/m2) & $110( \pm 37)$ & $102( \pm 36)$ & $106( \pm 27)$ & $110( \pm 27)$ & 0.31 \\
\hline RWT (mm) & $0.44( \pm 0.10)$ & $0.43( \pm 0.12)$ & $0.46( \pm 0.12)$ & $0.45( \pm 0.14)$ & 0.47 \\
\hline $\mathrm{E} / \mathrm{E}^{\prime}$ & $9.3( \pm 4.0)$ & $9.4( \pm 4.2)$ & $8.7( \pm 2.5)$ & $8.9( \pm 3.5)$ & 0.50 \\
\hline LA diameter & $38( \pm 4.5)$ & $38( \pm 4.7)$ & $38( \pm 5.1)$ & $38( \pm 5.3)$ & 0.54 \\
\hline LVEF (\%) & $58.0( \pm 4.2)$ & $58.0( \pm 3.5)$ & $58.4( \pm 3.1)$ & $57.6( \pm 5.4)$ & 0.69 \\
\hline Septal wall (mm) & $10.5( \pm 2.9)$ & $10.5( \pm 2.4)$ & $10.6( \pm 1.8)$ & $10.7( \pm 2.0)$ & 0.62 \\
\hline Posterior wall (mm) & $10.1( \pm 1.6)$ & $10.5( \pm 4.2)$ & $10.3( \pm 1.6)$ & $10.2( \pm 1.5)$ & 0.65 \\
\hline LVEDD (mm) & $47.8( \pm 4.9)$ & $45.4( \pm 9.3)$ & $46.3( \pm 5.8)$ & $47.4( \pm 7.0)$ & 0.26 \\
\hline LVESD (mm) & $29.6( \pm 6.2)$ & $28.3( \pm 7.5)$ & $30.0( \pm 4.5)$ & $26.1( \pm 7.5)$ & 0.17 \\
\hline $\mathrm{PVa}(\mathrm{cm} / \mathrm{sec})$ & $32.4( \pm 6.3)$ & $33.5( \pm 13.0)$ & $33.2( \pm 10.3)$ & $32.0( \pm 12.9)$ & 0.59 \\
\hline
\end{tabular}

$D C$ deceleration; IVRT isovolumetric relaxation time; $L V M I$ left ventricular mass index; $L V E F$ left ventricular ejection fraction; $L A$ left atrium; $L V E D D$ left ventricular end diastolic diameter; LVESD left ventricular end systolic diameter; PVa pulmonary vein atrial flow reversal. RWT relative wall thickness

pressure and the reduction in NT-proBNP $(r=0.26 ; p=0.019)$. Figure 3 shows that the decrease of NT-proBNP was largest in the highest tertile of drop of SBP between baseline and 6 months.

\section{Adverse events}

There were no serious adverse events reported. A total of 14 adverse events were reported in nine patients, without differences between groups.

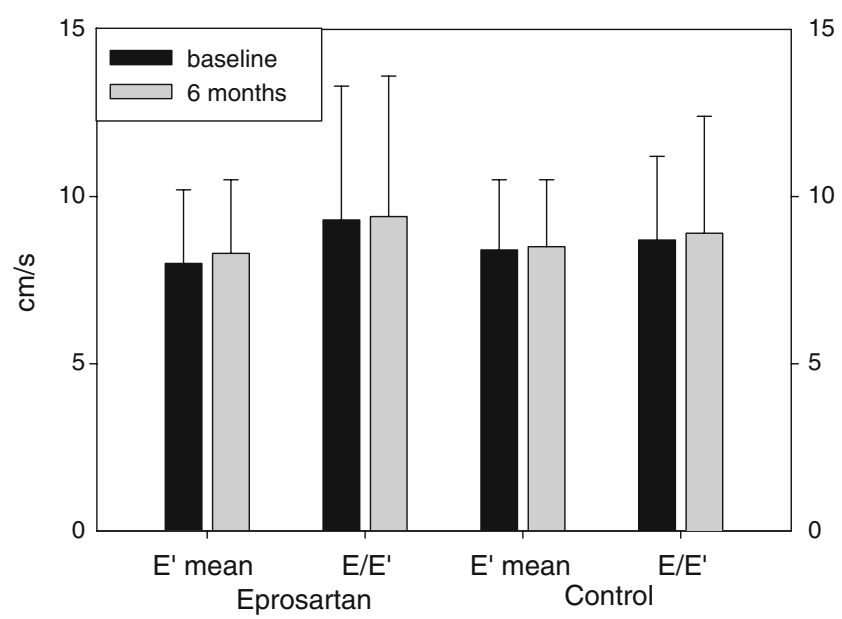

Fig. 2 Changes in diastolic function (mean tissue Doppler velocity E' mean and $\mathrm{E} / \mathrm{E}^{\prime}$ ) between baseline and after 6 months in the eprosartan and control group

\section{Discussion}

The present study shows that treatment with eprosartan and control treatment in hypertension patients with signs of diastolic dysfunction resulted in a rapid and sustained drop in both systolic and diastolic blood pressure. Despite this, diastolic function remained largely unchanged, both in the eprosartan group and in the control group, without any difference between the groups. Overall, no significant effects on neurohormones were found in both groups, although the reduction in systolic blood pressure was associated with the reduction in NT-proBNP.

No improvement of diastolic function after lowering blood pressure

Data on the effects of the treatment of blood pressure on diastolic function, measured with tissue Doppler, are scarce. A few studies demonstrated an improvement of diastolic function after blood pressure lowering therapies [7-11]. In contrast, one study did not demonstrate beneficial effects of losartan on diastolic function in patients with hypertension [12]. However, these studies either did not have a controlled design, or suboptimal echocardiographic measurements for diastolic function were used. Two randomised controlled studies demonstrated beneficial effect of blood lowering therapies on diastolic function in patients with hypertension $[6,13]$. In the Swedish Irbesartan Left Ventricular Hypertrophy Investigation vs Atenolol (SILVHIA) study, both 
Table 4 Laboratory changes in the eprosartan and control groups

\begin{tabular}{|c|c|c|c|c|c|c|c|c|}
\hline & \multicolumn{2}{|l|}{ Baseline } & \multicolumn{3}{|l|}{ 6months } & \multicolumn{3}{|l|}{ Change } \\
\hline & Eprosartan & Control & Eprosartan & Control & $p$-value & Eprosartan & Control & $p$-value \\
\hline NT-proBNP & $113( \pm 101)$ & $125( \pm 139)$ & $134( \pm 144)$ & $103( \pm 92)$ & 0.25 & $+21( \pm 98)$ & $-23( \pm 110)$ & 0.06 \\
\hline Aldosterone & $274( \pm 158)$ & $294( \pm 210)$ & $227( \pm 151)$ & $298( \pm 169)$ & 0.04 & $-45( \pm 130)$ & $-5( \pm 193)$ & 0.26 \\
\hline Renin & $15( \pm 11)$ & $54( \pm 120)$ & $15( \pm 8)$ & $14( \pm 12)$ & 0.26 & $+7( \pm 6)$ & $+5( \pm 10)$ & 0.72 \\
\hline $\mathrm{ACE}$ & $26( \pm 15)$ & $32( \pm 20)$ & $30( \pm 16)$ & $31( \pm 23)$ & 0.76 & $+2( \pm 12)$ & $-1( \pm 9)$ & 0.32 \\
\hline
\end{tabular}

irbesartan and atenolol improved diastolic function in 96 hypertensive patients [6]. In the VALIDD study, diastolic function at baseline was comparable with our study [13]. Mean TDI significantly decreased in both treatment arms, but not $\mathrm{E} / \mathrm{E}^{\prime}$. In contrast to our study, they found that patients with larger blood pressure reductions had larger improvements of diastolic function. In the Hong Kong diastolic heart failure study, patients with diastolic heart failure were randomised to either a diuretic alone, a diuretic plus an ACE-inhibitor, or a diuretic plus an angiotensin receptor blocker [17]. In this study, neither the ACE-inhibitor, nor the angiotensin receptor blocker (irbesartan) affected diastolic function, quality of life, or 6 min walk test [17]. In addition, similar to our study and VALIDD, no improvement in $\mathrm{E} / \mathrm{E}^{\prime}$ was seen, while there was only a modest improvement in mean TDI [17]. Therefore, evidence exists for a beneficial effect of blood pressure lowering therapy on diastolic function.

In contrast, our study did not demonstrate an improvement on diastolic function in patients with hypertension, despite a significant drop in blood pressure. One explanation might be that tissue Doppler values of the patients in the present were similar to those reported in an age-matched

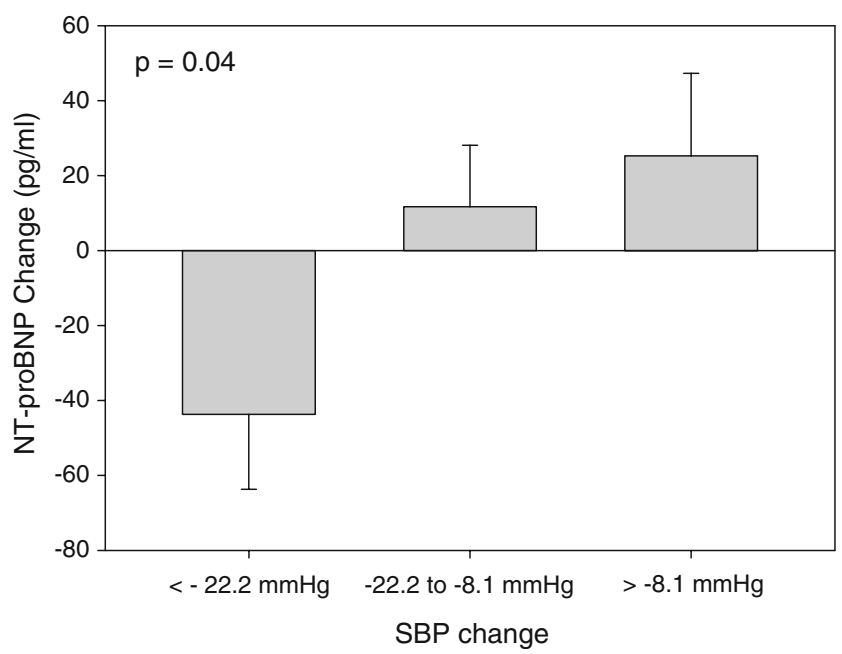

Fig. 3 Change in systolic blood pressure (SBP) from baseline to 6 months, divided in tertiles, related to changes in NT-proBNP general population [18]. However, diastolic function was comparable with patients in VALIDD, and worse compared with the SILVHIA study. Both in VALIDD and in SILVHIA, anti-hypertensive therapy improved diastolic function. A more likely explanation therefore might be that the treatment period of 6 months might not have been sufficient to show an effect on diastolic function. The association between lowering blood pressure and a decrease in NT-proBNP might indicate that although cardiac stress has diminished, this is not yet translated into structural cardiac changes.

No superiority of an angiotensin receptor blocker over other blood pressure lowering drugs

Our finding that eprosartan was not superior compared with other anti-hypertensive drugs in improving diastolic function is consistent with findings in VALIDD and the Hong Kong diastolic heart failure study $[13,17]$. In VALIDD, the effects of valsartan were not superior to control treatment in improving diastolic function [13]. In the Hong Kong heart failure study, the addition of ramipril or irbesartan to a diuretic was not better in improving diastolic function than a diuretic alone, although these patients were different from the present study, since they were all diasto0lic heart failure patients [17]. So, despite their marked effects on fibrosis and left ventricular hypertrophy, angiotensin receptor blockers do not seem to be superior to other anti-hypertensive drugs. Taken together with the finding that diastolic function did not improve after lowering of blood pressure in both groups, one might suggest that neither angiotensin receptor blockers nor other anti-hypertensive drugs have marked effects on the improvement of diastolic function. These findings might also explain why large randomised clinical trials with ACEinhibitors, angiotensin receptor blockers, and beta-blockers in patients with diastolic heart failure showed limited effects on clinical outcome [19-22].

Changes in neurohormonal markers after anti-hypertensive treatment

It is well known that ARBs lower aldosterone levels, as was also found in the present study. These findings were not 
influenced by the use of aldosterone blockers [23]. Overall, we did not find a significant drop in NT-proBNP, neither in the eprosartan nor in the control group. However, blood pressure reduction was related to a decrease in NT-proBNP. This might suggest that blood pressure lowering does result in a decrease in cardiac stress, which is not recognized or followed by a decrease in left ventricular hypertrophy or an improvement in diastolic function after 6 months of treatment. However, NT-proBNP might be a sensitive and early marker that might only translate into functional and structural changes after more than 6 months of treatment. In VALIDD, no data on (NT-pro)BNP are reported. In the Hong Kong diastolic heart failure study however, only the combination of diuretics and ramipril significantly reduced NT-proBNP, while diuretics alone or the combination of diuretics and irbesartan did not. Of note, all patients in the Hong Kong diastolic heart failure study had heart failure, while in our study only 20 patients $(21 \%)$ had heart failure. In the present study, a total of 20 patients were reported by their treating physician as having diastolic heart failure. However, patient characteristics, including systolic and diastolic left ventricular function and NT-proBNP were not significantly different between the groups. Therefore, although the diagnosis of heart failure in these patients is highly debatable, they did not differ from patients without heart failure, and did not influence the results.

\section{Limitations}

Several limitations of the present study should be noted. First, the most obvious reason for a lack of effect on diastolic function might be related to the duration of treatment of 6 months. It seems reasonable to believe that structural and functional cardiac changes only occur after a longer duration of treatment. The duration of 6 months was chosen, since an effect was anticipated already within 6 months. Second, diastolic function in these patients was not very poor. Mean $\mathrm{E}^{\prime}$ was $8.2 \mathrm{~cm} / \mathrm{s}$ and mean $\mathrm{E} / \mathrm{E}^{\prime}$ was 9.0 , indicating that diastolic function was only mildly impaired. However, data were comparable with the VALIDD study [13]. Third, patients were included on the basis of the traditional mitral valve inflow Doppler parameters. Patients were included when they had an inverted E/A ratio, and either an increased deceleration time or an increased isovolumetric relaxation time. At the time of initiation of the study, these measurements were usual clinical practice, although first reports on the superiority of tissue Doppler for the measurement of diastolic function were just presented. Fourth, the group was small, and this may have limited the power to detect smaller differences. Fifth, ACEinhibitors were allowed in both groups, which may have obscured the difference between RAS-blocked versus nonRAS blockade. In fact, in the eprosartan group, the use of ACE-inhibitors dropped from $40 \%$ to $27 \%$ after 6 months, while in the control group the use of ACE-inhibitors had slightly increased from $48 \%$ to $51 \%$.

Future perspectives

The present and other studies have indicated that the effects of lowering blood pressure, either with an angiotensin receptor blocker or with any other anti-hypertensive drug, do not seem to markedly improve diastolic function. In addition, large randomized clinical trials showed limited effects of ACE-inhibitors, angiotensin receptor blockers, or beta-blockers, on clinical outcome in patients with diastolic heart failure [19-22]. It therefore remains to be established how to treat diastolic heart failure [24, 25]. An interesting novel approach might be to prevent cardiac and vascular collagen crosslink formation with advanced glycation end product (AGE)-breakers [26, 27]. First data have indicated that these agents can improve diastolic function, and further phase II studies currently ongoing [28].

\section{Conclusion}

In patients with hypertension and mildly impaired diastolic function, neither eprosartan nor other anti-hypertensives did show any improvement in diastolic function or NT-proBNP after 6 months of treatment. However, lowering blood pressure was related to a decrease of NT-proBNP.

Acknowledgements This study was supported by an unrestricted research grant from Solvay Pharma the Netherlands.

Professor van Veldhuisen and Dr Voors are clinical established investigators of the Netherlands Heart Foundation (grant D97.017 and grant 2006T037). Dr Hartog is supported by the Netherlands Heart Foundation (grant 2006T012).

No potential conflicts of interest have been reported.

Open Access This article is distributed under the terms of the Creative Commons Attribution Noncommercial License which permits any noncommercial use, distribution, and reproduction in any medium, provided the original author(s) and source are credited.

\section{References}

1. Wang M, Yip G, Yu CM, Zhang Q, Zhang Y, Tse D, et al. Independent and incremental prognostic value of early mitral annulus velocity in patients with impaired left ventricular systolic function. J Am Coll Cardiol. 2005;45:272-7.

2. Klingbeil AU, Schneider M, Martus P, Messerli FH, Schmieder RE. A meta-analysis of the effects of treatment on left ventricular mass in essential hypertension. Am J Med. 2003;115:41-6.

3. López B, Querejeta R, Varo N, González A, Larman M, Martínez Ubago JL, et al. Usefulness of serum carboxy-terminal propeptide of procollagen type I in assessment of the cardioreparative ability of antihypertensive treatment in hypertensive patients. Circulation. 2001;104:286-91. 
4. Ciulla MM, Paliotti R, Esposito A, Dìez J, López B, Dahlöf B, et al. Different effects of antihypertensive therapies based on losartan or atenolol on ultrasound and biochemical markers of myocardial fibrosis: results of a randomized trial. Circulation. 2004;110:552-7.

5. Müller-Brunotte R, Kahan T, López B, Edner M, González A, Díez $\mathrm{J}$, et al. Myocardial fibrosis and diastolic dysfunction in patients with hypertension: results from the Swedish Irbesartan Left Ventricular Hypertrophy Investigation versus Atenolol (SILVHIA). J Hypertens. 2007;25:1958-66.

6. Müller-Brunotte R, Kahan T, Malmqvist K, Ring M, Edner M. Tissue velocity echocardiography shows early improvement in diastolic function with irbesartan and atenolol therapy in patients with hypertensive left ventricular hypertrophy. Results from the Swedish Irbesartan Left Ventricular Hypertrophy Investigation vs Atenolol (SILVHIA). Am J Hypertens. 2006;19:927-36.

7. Araujo AQ, Arteaga E, Ianni BM, Buck PC, Rabello R, Mady C. Effect of Losartan on left ventricular diastolic function in patients with nonobstructive hypertrophic cardiomyopathy. Am J Cardiol. 2005;96:1563-7.

8. Mattioli AV, Zennaro M, Bonatti S, Bonetti L, Mattioli G. Regression of left ventricular hypertrophy and improvement of diastolic function in hypertensive patients treated with telmisartan. Int J Cardiol. 2004;97:383-8.

9. Tanaka H, Oki T, Tabata T, Yamada H, Harada K, Kimura E, et al. Losartan improves regional left ventricular systolic and diastolic function in patients with hypertension: accurate evaluation using a newly developed color-coded tissue doppler imaging technique. J Card Fail. 2004;10:412-20.

10. Futai R, Ito T, Kawanishi Y, Terasaki F, Kitaura Y. Olmesartan ameliorates myocardial function independent of blood pressure control in patients with mild-to-moderate hypertension. Heart Vessels. 2009;24:294-300.

11. Wachtell K, Bella JN, Rokkedal J, Palmieri V, Papademetriou V, Dahlöf B, et al. Change in diastolic left ventricular filling after one year of antihypertensive treatment: the losartan intervention for endpoint reduction in hypertension (LIFE) study. Circulation. 2002;105:1071-6.

12. Zakynthinos E, Pierutsakos Ch, Konstantinidis K, Zakynthinos S, Papadogiannis D. Losartan reduces left ventricular hypertrophy proportionally to blood pressure reduction in hypertensives, but does not affect diastolic cardiac function. Angiology. 2004;55:669-78.

13. Solomon SD, Janardhanan R, Verma A, Bourgoun M, Daley WL, Purkayastha D, et al. Valsartan in diastolic dysfunction (VALIDD) investigators. Effect of angiotensin receptor blockade and antihypertensive drugs on diastolic function in patients with hypertension and diastolic dysfunction: a randomised trial. Lancet. 2007;369:2079-87.

14. Nagueh SF, Appleton CP, Gillebert TC, Marino PN, Oh JK, Smiseth OA, et al. Recommendations for the evaluation of left ventricular diastolic function by echocardiography. J Am Soc Echocardiogr. 2009;22:107-33.

15. Smilde TD, van Veldhuisen DJ, Navis G, Voors AA, Hillege HL. Drawbacks and prognostic value of formulas estimating renal function in patients with chronic heart failure and systolic dysfunction. Circulation. 2006;114:1572-80.

16. Mancia G, De Backer G, Dominiczak A, Cifkova R, Fagard R, Germano G, et al. The task force for the management of arterial hypertension of the European Society of Hypertension, The task force for the management of arterial hypertension of the European Society of Cardiology. 2007 Guidelines for the management of arterial hypertension: The Task Force for the Management of Arterial Hypertension of the European Society of Hypertension $(\mathrm{ESH})$ and of the European Society of Cardiology (ESC). Eur Heart J. 2007;28:1462-536.

17. Yip GW, Wang M, Wang T, Chan S, Fung JW, Yeung L, et al. The Hong Kong diastolic heart failure study: a randomised controlled trial of diuretics, irbesartan and ramipril on quality of life, exercise capacity, left ventricular global and regional function in heart failure with a normal ejection fraction. Heart. 2008;94:573-80.

18. Okura H, Takada Y, Yamabe A, Kubo T, Asawa K, Ozaki T, et al. Age- and gender-specific changes in the left ventricular relaxation: a Doppler echocardiographic study in healthy individuals. Circ Cardiovasc Imaging. 2009;2:41-6.

19. Yusuf S, Pfeffer MA, Swedberg K, Granger CB, Held P, McMurray JJ, et al. CHARM investigators and committees. Effects of candesartan in patients with chronic heart failure and preserved leftventricular ejection fraction: the CHARM-preserved trial. Lancet. 2003;362:777-81.

20. Massie BM, Carson PE, McMurray JJ, Komajda M, McKelvie R, Zile MR, et al. I-PRESERVE investigators. Irbesartan in patients with heart failure and preserved ejection fraction. N Engl J Med. 2008;359:2456-67.

21. Cleland JG, Tendera M, Adamus J, Freemantle N, Polonski L, Taylor J, et al. The perindopril in elderly people with chronic heart failure (PEP-CHF) study. Eur Heart J. 2006;27:2338-45.

22. Van Veldhuisen DJ, Cohen-Solal A, Böhm M, Anker SD, Babalis $\mathrm{D}$, Roughton M, et al. Beta-blockade with nebivolol in elderly heart failure patients with impaired and preserved left ventricular ejection fraction: data from SENIORS. J Am Coll Cardiol. 2009;53:2150-8.

23. van de Wal RM, Plokker HW, Lok DJ, Boomsma F, van der Horst FA, van Veldhuisen DJ, et al. Determinants of increased angiotensin II levels in severe chronic heart failure patients despite ACE inhibition. Int J Cardiol. 2006;106:367-72.

24. Voors AA, de Jong RM. Treating diastolic heart failure. Heart. 2008;94:971-2.

25. Dickstein K, Cohen-Solal A, Filippatos G, McMurray JJ, Ponikowski P, Poole-Wilson PA, et al. ESC guidelines for the diagnosis and treatment of acute and chronic heart failure 2008: the Task Force for the diagnosis and treatment of acute and chronic heart failure 2008 of the European Society of Cardiology. Developed in collaboration with the Heart Failure Association of the ESC (HFA) and endorsed by the European Society of Intensive Care Medicine (ESICM). Eur J Heart Fail. 2008;10:933-89.

26. Hartog JW, Voors AA, Bakker SJ, Smit AJ, van Veldhuisen DJ. Advanced glycation end-products (AGEs) and heart failure: pathophysiology and clinical implications. Eur J Heart Fail. 2007;9:1146-55.

27. Hartog JW, Voors AA, Schalkwijk CG, Scheijen J, Smilde TD, Damman K, et al. Clinical and prognostic value of advanced glycation end-products in chronic heart failure. Eur Heart J. 2007;28:2879-85.

28. Little WC, Zile MR, Kitzman DW, Hundley WG, O'Brien TX, Degroof RC. The effect of alagebrium chloride (ALT-711), a novel glucose cross-link breaker, in the treatment of elderly patients with diastolic heart failure. J Card Fail. 2005;11:191-5. 